
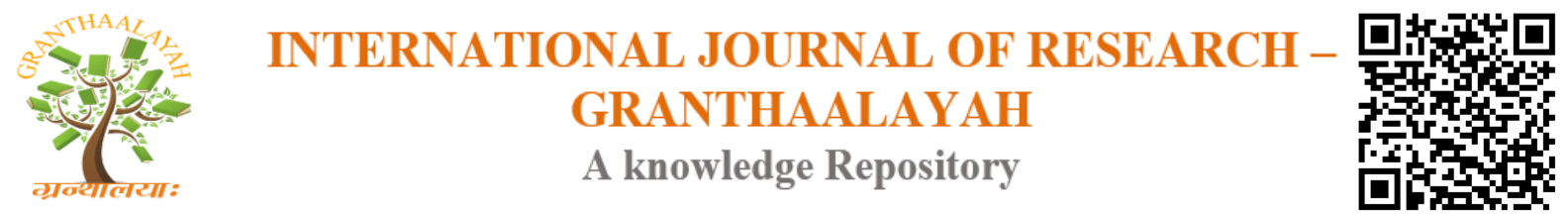

Science

\title{
REDUCTION OF REAL POWER LOSS BY LAVA HERON OPTIMIZATION ALGORITHM
}

\author{
Dr.K.Lenin *1 \\ ${ }^{* 1}$ Professor, Department of EEE, Prasad V.Potluri Siddhartha Institute of Technology, Kanuru, \\ Vijayawada, Andhra Pradesh -520007, India
}

\begin{abstract}
This paper presents a new Lava Heron Optimization (LHO) Algorithm for solving reactive power problem. This algorithm is inspired by the grab skill of the Lava Heron bird. Lava heron bird live in on the freshwater or saline water, swampy marshes or wetlands with tuft of trees mostly in low lying areas, where there are abundant convenience of fishes as their prey. By using the prey catching skill of the Lava Heron bird algorithm has been framed and utilized to minimize the real power loss. Proposed Lava Heron Optimization (LHO) Algorithm has been tested in standard IEEE 57,118 bus systems and simulation results demonstrate the commendable performance of the projected Lava Heron Optimization (LHO) Algorithm in reducing the real power loss.
\end{abstract}

Keywords: Lava Heron Optimization; Swarm Intelligence; Optimal Reactive Power; Transmission Loss.

Cite This Article: Dr.K.Lenin. (2017). "REDUCTION OF REAL POWER LOSS BY LAVA HERON OPTIMIZATION ALGORITHM.” International Journal of Research - Granthaalayah, 5(8), 85-93. https://doi.org/10.29121/granthaalayah.v5.i8.2017.2187.

\section{Introduction}

Optimal reactive power dispatch problem is one of the main problems in power systems. Main goal is to operate the system in secure mode and also to improve the economy of the system. Here the reactive power dispatch problem involves best utilization of the existing generator bus voltage magnitudes, transformer tap setting and the output of reactive power sources so as to minimize the loss and to enhance the voltage stability of the system. Various mathematical techniques have been utilized to Solve this optimal reactive power dispatch problem like the gradient method [1, 2], Newton method [3] and linear programming [4-7].The gradient and Newton methods failed to handle inequality constraints. In last few years several biological and natural processes have been utilized in the methodologies of science and technology in an increasing manner. Among the most popular nature inspired approaches are Particle Swarm Optimization [8], the artificial immune systems [9], the Ant Colony Optimization [10], etc. Also, a number of swarm intelligence algorithms, based on the behaviour of the bees have been 
presented [11]. These algorithms are divided, mainly, in two categories according to their behaviour in the nature, the foraging behaviour and the mating behaviour. The most important methodologies that simulate the foraging behaviour of the bees are the Artificial Bee Colony (ABC) Algorithm proposed by [12], the Virtual Bee Algorithm proposed by [13], the Bee Colony Optimization Algorithm proposed by [14], the Beehive algorithm proposed by [15], the Bee Swarm Optimization Algorithm proposed by [16] and the Bees Algorithm proposed by [17]. This paper presents a new Lava Heron Optimization (LHO) Algorithm for solving reactive power problem. Lava heron bird live in on the freshwater or saline water, swampy marshes or wetlands with tuft of trees mostly in low lying areas, where there are abundant convenience of fishes as their prey. These highly territorial birds are found in intertidal zones and mangrove swamps on all of the islands of Galápagos Province. The lava heron stalks small crabs and fish slowly before quickly spearing and eating them. They have also been known to eat the flies that gather near cacti. Lava herons are typically seen hunched over and they have a sharp alarm call [18]. The performance of Lava Heron Optimization (LHO) Algorithm has been evaluated in standard IEEE 57,118 bus systems and the result analysis shows that our projected approach outperforms all approaches examined in this paper.

\section{Problem Formulation}

The main objective of the reactive power dispatch problem is to minimize the real power loss .

\subsection{Minimization of Real Power Loss}

The main objective is to minmize the real power loss $\left(\mathrm{P}_{\text {loss }}\right)$ in transmission lines of a power system. This is stated as follows.

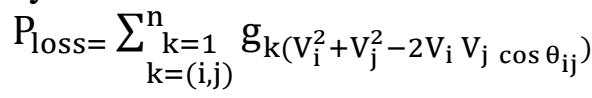

Where $\mathrm{n}$ is the number of transmission lines, $\mathrm{g}_{\mathrm{k}}$ is the conductance of branch $\mathrm{k}, \mathrm{V}_{\mathrm{i}}$ and $\mathrm{V}_{\mathrm{j}}$ are voltage magnitude at bus $i$ and bus $j$, and $\theta_{i j}$ is the voltage angle difference between bus $i$ and bus j.

\subsection{Minimization of Voltage Deviation}

It is very important to minimize the Deviations in voltage magnitudes (VD) at load buses. This is stated as follows.

Minimize VD $=\sum_{\mathrm{k}=1}^{\mathrm{nl}}\left|\mathrm{V}_{\mathrm{k}}-1.0\right|$

Where $\mathrm{nl}$ is the number of load busses and $\mathrm{V}_{\mathrm{k}}$ is the voltage magnitude at bus $\mathrm{k}$.

\subsection{System Constraints}

In the minimization of active power, there is two types of constraints, which one is equality and others are inequality .

Load flow equality constraints:

$P_{G i}-P_{D i}-V_{i \sum_{j=1}^{n b} V_{j}}\left[\begin{array}{cc}G_{i j} & \cos \theta_{i j} \\ +B_{i j} & \sin \theta_{i j}\end{array}\right]=0, i=1,2 \ldots, n b$ 
$Q_{G i}-Q_{D i}-V_{i \sum_{j=1}^{n b} V_{j}}\left[\begin{array}{cc}G_{i j} & \cos \theta_{i j} \\ +B_{i j} & \sin \theta_{i j}\end{array}\right]=0, i=1,2 \ldots, n b$

where, $n b$ is the number of buses, $P_{G}$ and $Q_{G}$ are the real and reactive power of the generator, $P_{D}$ and $Q_{D}$ are the real and reactive load of the generator, and $G_{i j}$ and $B_{i j}$ are the mutual conductance and susceptance between bus $i$ and bus $j$.

Inequality constraints are as follows,

Generator bus voltage $\left(V_{G i}\right)$

$V_{G i}^{\min } \leq V_{G i} \leq V_{G i}^{\max }, i \in n g$

Load bus voltage $\left(V_{L i}\right)$

$V_{L i}^{\min } \leq V_{L i} \leq V_{L i}^{\max }, i \in n l$

Switchable reactive power compensations $\left(Q_{C i}\right)$

$Q_{C i}^{\min } \leq Q_{C i} \leq Q_{C i}^{\max }, i \in n c$

Reactive power generation $\left(Q_{G i}\right)$

$Q_{G i}^{\min } \leq Q_{G i} \leq Q_{G i}^{\max }, i \in n g$

Transformers tap setting $\left(T_{i}\right)$ inequality constraint:

$T_{i}^{\min } \leq T_{i} \leq T_{i}^{\max }, i \in n t$

Transmission line flow $\left(\mathrm{S}_{\mathrm{Li}}\right)$ inequality constraint:

$S_{L i}^{\min } \leq S_{L i}^{\max }, i \in n l$

Where, nc, ng and nt are numbers of the switchable reactive power sources, generators and transformers.

\section{Lava Heron Optimization (LHO)Algorithm}

Lava heron bird live in on the freshwater or saline water, swampy marshes or wetlands with tuft of trees mostly in low lying areas, where there are abundant convenience of fishes as their prey. These highly territorial birds are found in intertidal zones and mangrove swamps on all of the islands of Galápagos Province. The lava heron stalks small crabs and fish slowly before quickly spearing and eating them. They have also been known to eat the flies that gather near cacti. Lava herons are typically seen hunched over and they have a sharp alarm call. These birds have little fear of humans. Unlike most herons, these birds nest in solitary pairs in either the lower branches of mangrove trees or under lava rocks. They can breed year-round, though typically from September to March, and can mate up to three times a year. The prey catching attribute of lava heron bird is being exploited as a meta-heuristic for solving the optimization problem.

\section{Inducement procedure}

The inducement process is similar to holding attraction in the beak by the lava heron bird, as it does and will dive at the appropriate place where there is possibility of a grab. Similarly in the calculation the inducement is a solution subset that is arbitrarily produced and is held by the lava heron bird prior to find a high-quality position through local exploration all over the complete solution set.

The three following progression depends on the happenings and it depends on the problem, its constraints, and the execution and partially on the possibility. Local exploration are given as follows, 
Fail To Spot - In this case the inducement gets established at one of its chosen place where it discover permanence and if the lava heron bird not succeeded to grab any prey and consequently the number of solutions in the solution set tends to raise. The absent node must be refurbished, in sequence to maintain the soundness of the solutions.

Grab - In this case the inducement helps the lava heron bird to grab a prey and thus the solution set elements remains steady and one appropriate element is added and one inappropriate element is eradicated.

Phony grab - Here the lava heron bird gets grip of a prey devoid of using inducement as occasionally fishes come close to the surface of the water. In this step an unsuitable element of the solution set is eradicated from the set. The exhaustion of a node in the form of a grab form the solution set must be reinstated for organization of soundness for definite constraints of the problems.

\section{Modifying Locations}

The Local exploration process can occur through assessment of all diminutive solution sets or part of extended enough solution sets. Depending on the solution sets for probable positions before it finds a appropriate one. This step is equivalent to the nature of the lava heron bird can sit very near the surface of the water such that at any point of time can take hold of a fish.

\section{Magnetize Victim Swarm}

In this step the point of discharge of the inducement will stay same but the complete set will swing to produce position for the most excellent agent to obtain the inducement and this will assist in an evolution like step where a move can change the solution particularly when the positions of the solution hold huge sense and the right progression is of greatest significance.

Articulate in a solution string represented as $S=\left\{a_{1}, a_{2}, \ldots, a_{n}\right\}$ and the lined segments are characterized as $\left\{b_{1}, b_{2}, \ldots, b_{n}\right\}$ where each $b_{i} \subseteq S$ and $=\{1,2, \ldots, m\}$,

Derivative Fitness $=m$

And with development of linkages $m$ will continually reduce. In this case we can use each of the subsets as nodes for link foundation.

For each unremitting variable of the fitness function of the problem that is where D is the dimension of the problem $x_{1} \in\left\{y_{t}^{1}, y_{t}^{2}, \ldots, y_{t}^{D}\right\}$ and $y_{t}^{D}$ is the $\mathrm{D}^{\text {th }}$ element in the $\mathrm{t}^{\text {th }}$ iteration. It encompasses the subsequent equations prevailing the variation of the variable's variation and is self-adaptive, preceding iteration based and error sensitive based on the fitness function of the $t$ and $\mathrm{t}-1$ iteration.

$y_{t}=y_{t-1}+\left|\left(y_{\text {best }}-y_{r}\right)\right|\left(y_{\text {best }}-y_{f}\right) \mid e_{(t, f)} \epsilon_{(t, f)}+$ bias

Where $\left[\left\{e_{(t, r)}, e_{(t, f)}\right\} \in e_{t}\right]$ and $\left[\left\{\epsilon_{(t, r)}, \in_{(t, f)}\right\} \in \epsilon_{t}\right]$ given by $e_{(t+1)}$ and $\epsilon_{(t+1)}$, where 
$e_{(t+1)}=\left\{\begin{array}{l}\frac{J_{t-1-} J_{t}}{\left|J_{t}-1\right|} \\ \frac{J_{t}-j_{t}-1}{\left|J_{t}-1\right|}\end{array} \quad\right.$ for $y_{t} \geq y_{t-1} \& y_{t}<y_{t-1}$

$\epsilon_{(t+1)}=\left\{\begin{array}{lc}\epsilon_{t} / k & \text { for } y_{t}>y_{\max } \\ \epsilon_{t} * k & \text { for } y_{t}<y_{\max } \\ \epsilon_{t} & \text { otherwise }\end{array}\right.$

For our reactive power problem with $\mathrm{J}_{\mathrm{t}}<\mathrm{J}_{\mathrm{t}}-1$ or $\mathrm{J}_{\mathrm{t}}>\mathrm{Jt}-1$ where $x_{t}^{1}$ is the $\mathrm{i}^{\text {th }}$ variable for iteration $\mathrm{t}, \mathrm{J}_{\mathrm{t}}$ is the fitness value at iteration $\mathrm{t}, \mathrm{y}_{f}$ and $\mathrm{y}_{r}$ are the front and rear neighbours respectively where

$y_{f}^{D} \in\left\{y_{t}^{D}\right.$ of new fellow agents $\} \quad$ and $y_{r} \in\left\{y_{t}^{D}\right.$ of previous fellow agents $\} \quad, \delta_{t}$ is the variations contributor with respect to the $\mathrm{t}^{\text {th }}$ iteration generated from previous iteration $\mathrm{t}-1, \in$ is the constantly changing adaptive contributor which denotes what percentage of the $\delta$ must be incorporated into the variable.

\section{Lava Heron Optimization (LHO) Algorithm for Solving Optimal Reactive Power Problem}

Stage 1: Initiate the Solution set all its $\mathrm{n}\left(\mathrm{n}=\right.$ dimension of problem) events $\left\{\mathrm{y}_{1}, \mathrm{y}_{2}, \ldots, \mathrm{y}_{\mathrm{n}}\right\}$.

Stage 2: Engender N Solution set each consist of element $\left\{\mathrm{y}_{1}, \mathrm{y}_{2}, \ldots, \mathrm{y}_{\mathrm{n}}\right\}$ denote an event.

Stage 3: Assess the fitness of each string.

Stage 4: Modernize the Global best if superior is found.

Stage 5: For each string Perform "Inducement procedure" where location is picked arbitrarily.

Stage 6: Execute "Modifying locations" operation depending upon the necessity and preliminary exploration results.

Stage 7: Execute "Magnetize Victim Swarm" and Complete "Inducement" operation.

Stage 8: Estimate the fitness of each string. Store the value of turnover if constraint fulfilled or else construct it zero.

Stage 9: on completion of every iteration, swap Y\% most awful solutions with arbitrary initialization. ( $\mathrm{Y}$ depends on $\mathrm{N}$ and according to the exploration necessity)

Stage 10: If numbers of iteration is completed then stop or else continue from stage 5.

\section{Simulation Results}

At first Lava Heron Optimization (LHO) Algorithm has been tested in standard IEEE-57 bus power system. The reactive power compensation buses are 18, 25 and 53. Bus 2, 3, 6, 8, 9 and 12 are PV buses and bus 1 is selected as slack-bus. The system variable limits are given in Table 1. The preliminary conditions for the IEEE-57 bus power system are given as follows:

$\mathrm{P}_{\text {load }}=12.119$ p.u. Q $_{\text {load }}=3.059$ p.u.

The total initial generations and power losses are obtained as follows:

$\sum P_{G}=12.442$ p.u. $\sum Q_{G}=3.3158$ p.u.

$\mathrm{P}_{\text {loss }}=0.25862$ p.u. $\mathrm{Q}_{\text {loss }}=-1.2064$ p.u.

Table 2 shows the various system control variables i.e. generator bus voltages, shunt capacitances and transformer tap settings obtained after optimization which are within the acceptable limits. In Table 3, shows the comparison of optimum results obtained from proposed methods with other optimization techniques. These results indicate the robustness of proposed approaches for providing better optimal solution in case of IEEE-57 bus system. 
Table 1: Variable Limits

\begin{tabular}{|c|c|c|c|c|c|c|c|c|}
\hline \multicolumn{9}{|c|}{ Reactive Power Generation Limits } \\
\hline Bus no & 1 & 2 & & 3 & 6 & 8 & 9 & 12 \\
\hline Qgmin & -1.4 & & 015 & -.02 & -0.04 & -1 & -0.0 & -0.4 \\
\hline Qgmax & 1 & 0 . & & 0.4 & 0.21 & 1 & 0.04 & 1.50 \\
\hline \multicolumn{9}{|c|}{ Voltage And Tap Setting Limits } \\
\hline vgmin & \multicolumn{2}{|c|}{ Vgmax } & \multicolumn{2}{|c|}{ vpqmin } & Vpqma & & tkmin & tkmax \\
\hline 0.9 & \multicolumn{2}{|c|}{1.0} & \multicolumn{2}{|c|}{0.91} & 1.05 & & & 1.0 \\
\hline \multicolumn{7}{|c|}{ Shunt Capacitor Limits } & 0.9 & \\
\hline Bus no & \multicolumn{2}{|c|}{18} & \multicolumn{2}{|c|}{25} & \multicolumn{2}{|l|}{53} & & \\
\hline Qcmin & \multicolumn{2}{|l|}{0} & \multicolumn{2}{|c|}{0} & \multicolumn{2}{|l|}{0} & & \\
\hline Qcmax & \multicolumn{2}{|l|}{10} & \multicolumn{2}{|c|}{5.2} & \multicolumn{2}{|l|}{6.1} & & \\
\hline
\end{tabular}

Table 2: Control variables obtained after optimization

\begin{tabular}{|l|l|}
\hline Control Variables & LHO \\
\hline V1 & 1.1 \\
\hline V2 & 1.038 \\
\hline V3 & 1.039 \\
\hline V6 & 1.028 \\
\hline V8 & 1.026 \\
\hline V9 & 1.002 \\
\hline V12 & 1.011 \\
\hline Qc18 & 0.0660 \\
\hline Qc25 & 0.200 \\
\hline Qc53 & 0.0478 \\
\hline T4-18 & 1.002 \\
\hline T21-20 & 1.047 \\
\hline T24-25 & 0.860 \\
\hline T24-26 & 0.870 \\
\hline T7-29 & 1.050 \\
\hline T34-32 & 0.873 \\
\hline T11-41 & 1.012 \\
\hline T15-45 & 1.030 \\
\hline T14-46 & 0.910 \\
\hline T10-51 & 1.020 \\
\hline T13-49 & 1.060 \\
\hline T11-43 & 0.910 \\
\hline T40-56 & 0.900 \\
\hline T39-57 & 0.950 \\
\hline T9-55 & 0.950 \\
\hline & \\
\hline &
\end{tabular}

Table 3: Comparison results

\begin{tabular}{|l|l|l|l|l|}
\hline S.No. & Optimization Algorithm & Finest Solution & Poorest Solution & Normal Solution \\
\hline 1 & NLP [19] & 0.25902 & 0.30854 & 0.27858 \\
\hline 2 & CGA [19] & 0.25244 & 0.27507 & 0.26293 \\
\hline
\end{tabular}




\begin{tabular}{|l|l|l|l|l|}
\hline 3 & AGA [19] & 0.24564 & 0.26671 & 0.25127 \\
\hline 4 & PSO-w [19] & 0.24270 & 0.26152 & 0.24725 \\
\hline 5 & PSO-cf [19] & 0.24280 & 0.26032 & 0.24698 \\
\hline 6 & CLPSO [19] & 0.24515 & 0.24780 & 0.24673 \\
\hline 7 & SPSO-07 [19] & 0.24430 & 0.25457 & 0.24752 \\
\hline 8 & L-DE [19] & 0.27812 & 0.41909 & 0.33177 \\
\hline 9 & L-SACP-DE [19] & 0.27915 & 0.36978 & 0.31032 \\
\hline 10 & L-SaDE [19] & 0.24267 & 0.24391 & 0.24311 \\
\hline 11 & SOA [19] & 0.24265 & 0.24280 & 0.24270 \\
\hline 12 & LM [20] & 0.2484 & 0.2922 & 0.2641 \\
\hline 13 & MBEP1 [20] & 0.2474 & 0.2848 & 0.2643 \\
\hline 14 & MBEP2 [20] & 0.2482 & 0.283 & 0.2592 \\
\hline 15 & BES100 [20] & 0.2438 & 0.263 & 0.2541 \\
\hline 16 & BES200 [20] & 0.3417 & 0.2486 & 0.2443 \\
\hline 17 & Proposed LHO & 0.22091 & 0.23010 & 0.22202 \\
\hline
\end{tabular}

Then Lava Heron Optimization (LHO) Algorithm has been tested in standard IEEE 118-bus test system [21].The system has 54 generator buses, 64 load buses, 186 branches and 9 of them are with the tap setting transformers. The limits of voltage on generator buses are $0.95-1.1$ per-unit., and on load buses are $0.95-1.05$ per-unit. The limit of transformer rate is $0.9-1.1$, with the changes step of 0.025 . The limitations of reactive power source are listed in Table 4 , with the change in step of 0.01 .

Table 4: Limitation of reactive power sources

\begin{tabular}{|l|l|l|l|l|l|l|l|}
\hline BUS & 5 & 34 & 37 & 44 & 45 & 46 & 48 \\
\hline QCMAX & 0 & 14 & 0 & 10 & 10 & 10 & 15 \\
\hline QCMIN & -40 & 0 & -25 & 0 & 0 & 0 & 0 \\
\hline BUS & 74 & 79 & 82 & 83 & 105 & 107 & 110 \\
\hline QCMAX & 12 & 20 & 20 & 10 & 20 & 6 & 6 \\
\hline QCMIN & 0 & 0 & 0 & 0 & 0 & 0 & 0 \\
\hline
\end{tabular}

The statistical comparison results of 50 trial runs have been list in Table 5 and the results clearly show the better performance of proposed Lava Heron Optimization (LHO) Algorithm in reducing the real power loss.

Table 5: Comparison results

\begin{tabular}{|l|l|l|l|l|}
\hline Active power loss (MW) & $\begin{array}{l}\text { BBO } \\
{[\mathbf{2 2}]}\end{array}$ & $\begin{array}{l}\text { ILSBBO/strategy1 } \\
{[\mathbf{2 2}]}\end{array}$ & $\begin{array}{l}\text { ILSBBO/strategy1 } \\
{[\mathbf{2 2}]}\end{array}$ & $\begin{array}{l}\text { Proposed } \\
\text { LHO }\end{array}$ \\
\hline Min & 128.77 & 126.98 & 124.78 & 116.72 \\
\hline Max & 132.64 & 137.34 & 132.39 & 119.94 \\
\hline Average & 130.21 & 130.37 & 129.22 & 117.02 \\
\hline
\end{tabular}

\section{Conclusion}

In this paper a novel approach Lava Heron Optimization (LHO) Algorithm used to solve optimal reactive power problem. Mainly inducement process, Modifying locations, Magnetize Victim 
Swarm has been utlized to solve the problem. The proposed approach has been tested in standard IEEE 57,118 bus systems. The simulation results indicate the efficiency and heftiness of the projected algorithm in reducing the real power loss.

\section{References}

[1] O.Alsac,and B. Scott, "Optimal load flow with steady state security", IEEE Transaction. PAS 1973, pp. 745-751.

[2] Lee K Y ,Paru Y M , Oritz J L -A united approach to optimal real and reactive power dispatch , IEEE Transactions on power Apparatus and systems 1985: PAS-104 : 1147-1153

[3] A.Monticelli , M .V.F Pereira , and S. Granville , "Security constrained optimal power flow with post contingency corrective rescheduling", IEEE Transactions on Power Systems :PWRS-2, No. 1, pp.175-182., 1987.

[4] Deeb N, Shahidehpur S.M, Linear reactive power optimization in a large power network using the decomposition approach. IEEE Transactions on power system 1990: 5(2) : 428-435

[5] E. Hobson ,'Network consrained reactive power control using linear programming, ' IEEE Transactions on power systems PAS -99 (4),pp 868-877, 1980

[6] K.Y Lee , Y.M Park, and J.L Oritz, "Fuel -cost optimization for both real and reactive power dispatches", IEE Proc; 131C,(3), pp.85-93.

[7] M.K. Mangoli, and K.Y. Lee, "Optimal real and reactive power control using linear programming”, Electr.Power Syst.Res, Vol.26, pp.1-10,1993.

[8] Kennedy, J., Eberhart, R.:"Particle swarm optimization", IEEE International Conference on Neural Networks 4, 1942-1948 (1995)

[9] Dasgupta, D. (ed.): “Artificial immune systems and their application”, Springer, Heidelberg (1998)

[10] Dorigo, M., Stützle, T.: Ant colony optimization. A Bradford Book. The MIT Press, Cambridge (2004)

[11] Baykasoglu, A., Ozbakir, L., Tapkan, P.: “Artificial bee colony algorithm and its application to generalized assignment problem”, In: Chan, F.T.S., Tiwari, M.K. (eds.) Swarm Intelligence, Focus on Ant and Particle Swarm Optimization, pp. 113-144. I-Tech Education and Publishing (2007)

[12] Karaboga, D., Basturk, B.: "On the performance of artificial bee colony (ABC) algorithm", Appl. Soft Comput. 8, 687-697 (2008)

[13] Yang, X.S.: "Engineering optimizations via nature-inspired virtual bee algorithms", In: Mira, J., Álvarez, J.R. (eds.) IWINAC 2005. LNCS, vol. 3562, pp. 317-323. Springer, Heidelberg (2005)

[14] Teodorovic, D., Dell'Orco, M.: Bee colony optimization - "A cooperative learning approach to complex transportation problems", Advanced OR and AI Methods in Transportation. In: Proceedings of the 16th Mini - EURO Conference and 10th Meeting of EWGT, pp. 51-60 (2005)

[15] Wedde, H.F., Farooq, M., Zhang, Y.: BeeHive: "An efficient fault-tolerant routing algorithm inspired by honey bee behavior”, In: Dorigo, M., Birattari, M., Blum, C., Gambardella, L.M., Mondada, F., Stützle, T. (eds.) ANTS 2004. LNCS, vol. 3172, pp. 83-94. Springer, Heidelberg (2004)

[16] Drias, H., Sadeg, S., Yahi, S.: "Cooperative bees swarm for solving the maximum weighted satisfiability problem”, In: Cabestany, J., Prieto, A.G., Sandoval, F. (eds.) IWANN 2005. LNCS, vol. 3512, pp. 318-325. Springer, Heidelberg (2005)

[17] Pham, D.T., Ghanbarzadeh, A., Koc, E., Otri, S., Rahim, S., Zaidi, M.: "The bees algorithm - A novel tool for complex optimization problems", In: IPROMS 2006 Proceeding 2nd International Virtual Conference on Intelligent Production Machines and Systems, Oxford. Elsevier, Amsterdam (2006). 
[18] C. Sur, A. Shukla, "Dealing QAP \& KSP with Green Heron Optimization Algorithm - A New Bio-Inspired Meta-heuristic", 4th International Conference on Computing, Communication and Networking Technologies (ICCCNT 2013), 4-6 July 2013, Tiruchengode, Tamil Nadu, India.

[19] Chaohua Dai, Weirong Chen, Yunfang Zhu, and Xuexia Zhang, "Seeker optimization algorithm for optimal reactive power dispatch,” IEEE Trans. Power Systems, Vol. 24, No. 3, August 2009, pp. 1218-1231.

[20] J. R. Gomes and 0. R. Saavedra, "Optimal reactive power dispatch using evolutionary computation: Extended algorithms," IEE Proc.-Gener. Transm. Distrib.. Vol. 146, No. 6. Nov. 1999.

[21] IEEE, "The IEEE 30-bus test system and the IEEE 118-test system", (1993), http://www.ee.washington.edu/trsearch/pstca/.

[22] Jiangtao Cao, Fuli Wang and Ping Li, "An Improved Biogeography-based Optimization Algorithm for Optimal Reactive Power Flow" International Journal of Control and Automation Vol.7, No.3 (2014), pp.161-176.

\footnotetext{
*Corresponding author.

E-mail address: gklenin@ gmail.com
} 